\title{
Catur Guru Dalam Seni Pertunjukan Wayang Wong Millenial
}

\author{
Ni Made Ruastiti', I Komang Sudirga ${ }^{2}$, I Gede Yudarta ${ }^{3}$ \\ ${ }^{1}$ Seni Tari, Fakultas Seni Pertunjukan, Institut Seni Indonesia Denpasar, \\ Jl. Nusa Indah, Denpasar, 80235, Indonesia \\ ${ }^{2}$ Seni Karawitan, Fakultas Seni Pertunjukan, Institut Seni Indonesia Denpasar, \\ Jl. Nusa Indah, Denpasar, 80235, Indonesia \\ ${ }^{3}$ Seni Karawitan, Fakultas Seni Pertunjukan, Institut Seni Indonesia Denpasar, \\ 1. Nusa Indah, Denpasar, 80235, Indonesia \\ maderuastiti@isi-dps.ac.id
}

Karya ilmiah ini bertujuan membahas konsep dan implementasi Catur Guru dalam Seni Pertunjukan Wayang Wong Millenial (sebuah model seni pertunjukan baru yang dirancang khusus bagi generasi millenial). Sebagai hasil penelitian kualitatif, pengumpulan data dilakukan melalui studi dokumen, observasi dan wawancara mendalam dengan beberapa informan, yakni pendidik, wakil seniman dan pengamat sosial budaya Bali. Semua data yang terkumpul dianalisis secara kualitatif deskriptif dengan mengunakan teori pedagogik dan teori tindakan sosial Bourdeau. Hasil penelitian menunjukkan bahwa : Pertama, Catur Guru merupakan konsep pendidikan yang meliputi guru swadyaya, yakni Tuhan Yang Maha Esa, guru wisesa (pemerintah), guru pengajian (guru di sekolah), dan guru rupaka (orang tua di rumah). Kedua, Seni Pertunjukan Wayang Wong Millenial yang benampilkan lakon Cupu Manik Astagina mengimplementasi ajaran Catur Guru, yakni (1) menggugah kesadaran untuk senantiasa berbakti kepada Tuhan (guru swadyaya), (2) adanya peran dan dukungan pihak pemerintah untuk merawat dan mengembangkan Seni Pertunjukan Wayang Wong (guru wisesa), (3) adanya peran pendidik di sekolah yang membimbing para siswanya agar mencintai seni-budaya bangsanya; dan (4) adanya peran orang tua dalam mendidik putra-putrinya (guru rupaka). Seni Pertunjukan Wayang Wong Millenial juga mengajarkan agar generasi muda Bali “melek teknologi”. Anak-anak yang terlibat sebagai pemain Wayang Wong Millenial diharapkan mampu berpikir kreatif, terampil, komunikatif, kolaboratif, kritis serta siap bersaing dalam arus kompetisi global. Guru dan orang tua siswa perlu mendampingi anaknya dalam mengakses internet untuk mendukung pertumbuhan fisik, perkembangan sosial, intelektual dan kecerdasan spiritual mereka.

Kata kunci : catur guru, pertunjukan wayang wong, generasi millenial.

\section{Catur Guru in Millennial Wayang Wong Performing Arts}

This scientific work aims to discuss the concept and implementation of Catur Guru in the Millennial Wayang Wong Performing Arts. As a result of qualitative research, data collection was carried out through document study, observation, and in-depth interviews with dance teachers, artist representatives, and Balinese sociocultural observers. All data collected were analyzed qualitatively using pedagogical theory and social action theory. The results showed that : First, Catur Guru is an educational concept that includes Guru Swadyaya (God Almighty), Guru Wisesa, Guru Pengajian, and Guru Rupaka. Second, the Wayang Wong Millennial performance art tells the story of Cupu Manik Astagina. Cupu Manik Astagina is a form of the implementation of Catur Guru, namely : 1) arousing awareness to always serve God as a self-help teacher, 2) the role and support of government officials as Guru Wisesa to support, care and mediate the educational process relate the Wayang Wong Bali, 3) the role of teachers in schools as Guru Pengajian, who guide their students to love the arts and culture of their nation and, 4) the role of parents as in educating their children. Wayang Wong Millennial also teaches Balinese children, who involved as Millennial Wayang Wong artist are expected to be creative, skilled at communicating, able to work together and collaborate, be able to think critically and be ready to compete in global competitions. In that case, teachers and parents of students need to assist their children in accessing online sites to support their physical growth and social and spiritual quotion.

Keywords : catur guru, millennial wayang wong performance, education, bali.

Proses Review : 1 - 30 Juni 2021, Dinyatakan Lolos: 15 Juli 2021 


\section{PENDAHULUAN}

Kemajuan suatu bangsa secara mendasar sangat ditentukan oleh adanya pendidikan yang berkualitas. Kualitas pendidikan dapat dilihat dalam dua hal, yakni mengacu pada proses pendidikan dan hasil pendidikan. Proses pendidikan disebut bermutu apabila seluruh komponen pendidikan terlibat dalam proses pendidikan itu sendiri. Faktor-faktor dalam proses pendidikan adalah berbagai input, seperti bahan ajar, metodologi, sarana sekolah, dukungan administrasi, sarana prasarana dan sumber daya lainnya serta penciptaan suasana kondusif. Sedangkan mutu pendidikan dalam konteks hasil pendidikan mengacu pada prestasi yang dicapai oleh sekolah pada setiap kurun waktu tertentu (Suryosubroto, 2004: 210).

Pendidikan perlu dikembangkan sesuai dinamika zaman. Memasuki arus revolusi industri 4.0 ini, dunia pendidikan diharapkan mampu mencetak sumber daya manusia Indonesia siap bersaing secara cepat dalam menyikapi permintaan dan tantangan global. Hanya melalui dunia pendidikan insan yang berkualitas dapat terlahir. Pendidikan yang dipengaruhi oleh revolusi industri 4.0, antara lain dicirikan dengan adanya pemanfaatan teknologi digital dalam proses pembelajaran berbasis sistem siber (cybergogy).

Tantangan pendidikan dalam arus revolusi industri 4.0 di Indonesia bukan lagi hanya berbicara pada masalah klasik, seperti pemerataan dan pemenuhan akses, sarana prasarana pendidikan saja tetapi juga berbicara mutu lulusan yang mampu bersaing dalam perkembangan pasar kerja transnasional. Oleh sebab itu, pendidik dituntut untuk bisa beradaptasi dengan tuntutan perkembangan zaman, dituntut menguasai lebih dahulu teknologi agar dapat menyesuaikan dengan peserta didik, jangan sampai peserta didik sudah memasuki era digital 4.0 sedangkan guru masih bergelut pada era 3.0. Bilamana situasinya demikian, maka dipastikan kondisinya akan pincang sehingga tujuan pendidikan lebih sulit tercapai (Ruastiti dkk, 2021).

Menurut Sistem Pendidikan Nasional UU No. 20 Tahun 2003, cakupan pendidikan di Indonesia meliputi pendidikan anak usia dini, pendidikan dasar, pendidikan menengah, dan pendidikan tinggi yang keseluruhannya merupakan kesatuan sistemik. Pendidikan usia dini dan pendidikan dasar memiliki makna penting karena pada fase pendidikan ini, dipersiapkan generasi penerus masa depan sebuah bangsa. Anak-anak dalam usia pendidikan dasar termasuk dalam masa golden age yang menentukan mereka kelak jika dewasa, baik dari segi fisik, mental maupun kecerdasan (Rokhman dkk, 2014). Di masa usia golden age inilah pendidikan karakter diperlukan untuk menyiapkan generasi penerus bangsa berkualitas di masa depan. Dalam kaitan ini, Lase (2019) menyatakan bahwa perubahan harus dilakukan di sekolah sehingga sumber daya manusia yang dihasilkan oleh berbagai lembaga pendidikan dapat berdedikasi terhadap negeri sekaligus berkontribusi secara global. Kurikulum juga harus dapat membentuk siswa dengan penekanan pada bidang STEM, merujuk pada pembelajaran berbasis TIK, internet of things, big data dan komputer serta kewirausahaan. Selain guru memiliki kompetensi mendidik, literasi digital, competence in future strategies dan konseling juga perlu memiliki sikap ramah teknologi, kolaborasi, kreatif dalam mengambil resiko, memiliki selera humor yang baik serta mengajar secara holistik. Sekolah dan guru perlu mempertimbangkan pembelajaran terbuka dan daring dalam memutuskan bagaimana menyelenggarakan pembelajaran.

Rokhman dkk (2014) menyatakan bahwa ketika pendidikan sudah menjadi bagian dari proses pembentukan karakter manusia unggul, maka dapat dikatakan mereka sudah siap untuk perubahan global. Secara fundamental, Indonesia akan menjadi bangsa yang kuat dalam semua sektor pada tahun 2045 atau 100 tahun setelah Indonesia merdeka. Keadaan ini didukung oleh pertumbuhan perekonomian Indonesia yang potensial dan diprediksi kuat berkembang menjadi negara rangking tujuh terbaik didunia pada tahun 2030. Dalam konteks itu, pemerintah Indonesia percaya bahwa perkembangan generasi penerus bangsa mampu menjadikan Indonesia sebagai bangsa yang kuat pada tahun 2045, jika proses pendidikan di Indonesia sudah merefleksikan beberapa nilai penting membangun mereka menjadi generasi muda yang berkarakter bangsa.

Ruastiti dkk (2019) menyebutkan bahwa karakter dapat dimaknai sebagai pendidikan nilai, pendidikan budi pekerti, pendidikan moral, pendidikan watak yang bertujuan mengembangkan kemampuan siswa untuk memberikan keputusan terbaik, teguh serta mampu menjunjung tinggi etika dan susila. Ada beberapa pihak yang sangat mempengaruhi terbentuknya karakter anak seperti keluarga, lingkungan masyarakat, komunitas, teman sepergaulan dan lingkungan sekolah. Kegagalan penanaman karakter pada seseorang sejak usia dini akan membentuk pribadi yang bermasalah di masa dewasanya kelak. Memiliki akhlak mulia tidak secara otomatis begitu manusia dilahirkan, namun memerlukan proses panjang melalui proses pengasuhan, pendampingan dan pembelajaran.

Upaya pendidikan kepada generasi penerus bisa dilakukan melalui media seni-budaya, seperti seni pewayangan (Pradana, 2012). Seni Pertunjukan Wayang Wong sebagai salah satu seni pewayangan tidak hanya berfungsi sebagai hiburan, tetapi juga sebagai tuntunan Pendidikan yang menguatkan makna pentingnya pembelajaran ilmu pengetahuan dan terampil dalam menggunakan teknologi. Kesenian wayang dapat dipakai sebagai sebuah media pembelajaran tentang kehidupan mulai dari sensitivitas, sensibilitas, etika, demokratisasi bahkan pembelajaran 
kehidupan dalam suasana pluralisme (Endraswara, 2013; Rahman, 2008; Pradana, 2018).

Nilai-nilai luhur yang terkandung dalam kebudayaan dapat menjadi sumber pendidikan dan pembentukan praktik bernilai unggul (Pradana dkk, 2016; Pradana dan Pratiwi, 2020; Pradana dan Pratiwi, 2021). Nilai-nilai luhur universal atau nilai pendidikan yang terkandung dalam seni pewayangan bisa dijadikan wahana bagi pembentukan karakter generasi Millenial Bali. Dalam kaitan ini, terdapat sembilan pilar karakter yang berasal dari nilai-nilai luhur universal, yaitu : (1) karakter keimanan; (2) kemandirian dan tanggung jawab; (3) berintegritas; (4) hormat dan santun; (5) kooperatif; (6) percaya diri dan pekerja keras; (7) komunikatif dan adil; (8) baik dan rendah hati; (9) karakter berjiwa besar, cinta damai dan mengedepankan integrasi (Lickona, 1991: 12-22; Tyas, 2018: 182-190).

Sebagai upaya pembentukan watak bangsa, pendidikan karakter bagi generasi penerus amatlah penting. Pendidikan karakter dipandang urgen oleh pemerintah Indonesia. Didalam Nawacita yang dirumuskan oleh Kabinet Indonesia Kerja (2014-2019), disebutkan ada beberapa karakter yang perlu dimiliki oleh setiap insan Indonesia. Karakter-karakter ini kemudian dipertegas lagi dalam Perpres 164 No. 87 Tahun 2017 tentang Penguatan Pendidikan Karakter yang mengamanatkan sistem pendidikan nasional untuk menanamkan beberapa nilai karakter yakni nilai religius, integritas, tenggang rasa, disiplin, bekerja keras, kreatif, mandiri, demokratis, teguh, cinta tanah air, komunikatif, cinta damai, haus prestasi dan peduli lingkungan.

Dalam upaya membangun karakter generasi penerus tidak hanya memberikan bekal mereka profesionalitas dan skill sesuai tantangan millennial masa depan, tetapi juga harus tetap bertumpu pada nilai-nilai budaya bangsa (Fathurrohman, 2016). Dalam membentuk karakter kepribadian generasi penerus, tidak kalah pentingnya pemberkatan tuhan terhadap usaha holistik maupun kolaborasi sinergis antara guru di sekolah, orang tua di rumah serta pihak pemerintah yang menyiapkan kebijakan dan memfasilitasi proses Pendidikan untuk peserta didik. Dalam kaitan ini, masyarakat Hindu Bali memiliki prinsip pendidikan berbasis kearifan lokal, yakni konsep catur guru yang meliputi : guru di sekolah (guru pengajian) dan orang tua (guru rupaka), pemerintah (guru wisesa) dan Ida Sang Hyang Widhi Wasa (Guru Swadhyaya) yang telah bersedia memberikan ilham, bakat dan mengabulkan permintaan manusia (Lastini dan Anggreni, 2018).

Konsep pendidikan Catur Guru antara lain terkandung dalam Seni Pertunjukan Wayang Wong yang dimiliki oleh masyarakat Hindu Bali. Sehubungan dengan hal ini, kini telah dikembangkan model Seni Pertunjukan Wayang Wong Millenial yang melibatkan generasi Millenial di Bali. Tidak kurang dari 120 anak-anak terlibat sebagai pemain. Dalam pengembangan model Seni Pertunjukan Wayang Wong ini yang melibatkan generasil millennial ini, ditampilkan lakon Cupu Manik Astagina (CMA). CMA merupakan benda ajaib yang diperebutkan oleh keluarga Resi Gotama. Inti dari kisah epos Ramayana ini adalah tentang keharusan generasi Millenial yang mencari ilmu pengetahuan sebagai bekal hidup menghadapai tantangan pesaingan revolusi Industri 4.0 (Rai S. dkk, 2020). Karya ilmiah ini membahas : (1) Bagaimana konsep pendidikan catur guru dalam kehidupan masyarakat Hindu Bali?; (2) Bagaimana implementasi catur guru dalam membentuk karakter anak-anak sebagai pelaku maupun penonton pertunjukan tersebut?.

\section{METODE PENELITIAN}

Penelitian yang mengkaji tentang konsep dan implementasi Catur Guru dalam Seni Pertunjukan Wayang Wong Millenial ini dilaksanakan di Bali. Seorang melakukan perjalan ke suatu lokasi diantaranya karena memiliki motivasi (Pradana, 2019). Demikian terdapat beberapa alasan terkait dengan penentuan lokasi penelitian adalah : (a) Catur Guru adalah konsep pendidikan yang merupakan bagian dari budaya masyarakat Hindu Bali; (b) Konsep pendidikan Catur Guru terdapat dalam Seni Pertunjukan Wayang Wong Millenial; (c) Konsep pendidikan Catur Guru amat penting diimplementasikan dalam pembentukan karakter generasi penerus.

Objek utama dari penelitian ini adalah Seni Pertunjukan Wayang Wong Inovasi dengan lakon Cupu Manik Astagina. Pengemasan Inovasi Wayang Wong ini diinisiasi oleh tim Peneliti dari Insititut Seni Indonesia (ISI) Denpasar yang bekerjasama dengan Sanggar Seni Puripurna, Gianyar. Karya tulis ini merupakan hasil penelitian yang dilakukan dengan menggunakan metode kualitatif dengan pendekatan kajian budaya. Data dikumpulkan melaui studi dokumen, observasi pementasan wayang wong, dan wawancara mendalam dengan beberapa informan dari unsur pelaku seni pewayangan, masyarakat pecinta seni pewayangan serta pemerhati seni pewayangan di Kota Denpasar dan Kabupaten Gianyar. Analisis deskriptif dan interpretatif dilakukan dengan mengaplikasikan teori semiotika dan teori tindakan Bourdeau.

\section{PENGERTIAN CATUR GURU DALAM KEBUDAYAAN BALI}

Umat Hindu Bali memiliki kearifan lokal di bidang pendidikan, yakni konsep pendidikan catur guru (Astawa, 2017; Sartika dkk, 2020). Konsep Catur Guru yang dimaksud dalam Hindu adalah mencakup empat guru sebagai berikut. Pertama, Guru Swadhyaya yakni Ida Sang Hyang Widhi Wasa (Tuhan Yang Maha Esa) adalah maha Guru sebagai sumber pemberi tuntunan hidup manusia melalui ajaran-ajaran sucinya yang diturunkan dalam bentuk wahyu yang diterima oleh para maha Rsi. Melalui 
keyakinan yang tinggi melaksanakan segala tuntunan dan menghindari semua yang tidak diperkenankan akan membawa manusia ke alam pembebasan. Sradha dan Bhakti melahirkan kekuatan untuk mempelajari ajarannya, terinternalisasi dalam diri pribadi dan tercermin dalam perwujudan perilaku yang baik, jujur, kasih sayang, tolong menolong, tenggang rasa, menjauhi kekerasan serta menghormati ciptaan-Nya.

Kedua, guru wisesa yakni pemerintah yang memiliki taggunghjawab dalam pengembangan kebijakan, termasuk kebijakan di bidang pendidikan. Pihak pemerintah juga memiliki kewenangan dalam menyiapkan fasilitas dan pengembangan sumber daya pendidikan termasuk tenaga pendidik, sarana dan prasarana pendidikan. Pemerintah wajib menerapkan regulasi pendidikan, meminimalisir media atau tayangan yang tidak mendidik, termasuk memblokir situs pornografi dan pornoaksi di dunia maya yang berpotensi menyesatkan generasi penerus.

Ketiga, guru pengajian, yakni guru di sekolah. Guru di sekolah tidak hanya mengajar tetapi juga mendidik seperti mengarahkan anak didik untuk bisa bersopan santun dalam bertindak dan menghadapi orang lain di masyarakat, memberi contoh perilaku yang baik. Tugas guru memang mengajarkan ilmu pengetahuan tetapi harus dihindari pembelajaran yang hanya sekedar tau konsep tetapi tidak dapat diaplikasikan untuk hidup di sektor publik. Sejalan dengan tantangan era revolusi industri 4.0, tidak hanya para siswa melainkan para guru di sekolah pun dituntut menguasai keahlian baru berbasis teknologi canggih dan ramah terhadap tantangan peradaban global.

Sejalan dengan tantangan peradaban global pada era digital, para guru harus mampu mengarahkan siswanya menggunakan internet secara cerdas, mampu mempersiapkan bahan dan literasi baru untuk proses pendidikan formal. Literasi lama yang mengandalkan baca, tulis dan menghitung harus diperkuat dengan mempersiapkan literasi baru yaitu literasi digital bagi keperluan membuat paper dan mempresentasikan, problem solving, membuat laporan kelompok serta menyelesaikan kuis online. Disini, literasi data sangat diperlukan untuk menunjang kemampuan analisis data dalam rangka menyelesaikan tugas-tugas kelas. Kemudian, literasi teknologi tidak kalah pentingnya untuk meningkatkan kecepatan dan efisiensi kerja dalam kegiatan pendidikan. Sedangkan literasi sumber daya manusia juga diperlukan untuk pengembangan kemampuan berinteraksi dengan baik, tidak kaku dan berkarakter yang diperlukan selama proses pengembangan potensi siswa. Guru harus mampu mengembangkan berbagai potensi yang dimilik siswanya (Mukhlis, 2009; Kompri, 2015).

Keempat, guru rupaka, yakni orang tua siswa yang bersangkutan. Orang tua adalah orang yang harus berperan menanamkan nilai-nilai utama yang pertama kalinya sejak siswa tersebut baru dilahirkan hingga menjadi dewasa. Orang tua hendaknya jangan melempar seluruhnya tanggung jawabnya kepada guru di sekolah. Mengingat nilai-nilai pendidikan yang terinternalisasi di rumah juga berpengaruh besar terhadap wawasan dan keterampilan mereka dalam masyarakat. Orang tua pun diharapkan mampu memotivasi dan mendorong sesuai apa yang diungkapkan oleh ki Hajar Dewantara yaitu Ing Ngarso Sung Tulodo, Ing Madyo Mangun Karso, Tut WuRi Handayani (Natalia, 2021).

\section{IMPLEMENTASI CATUR GURU DALAM SENI PERTUNJUKAN WAYANG WONG MILLENIAL}

Seni Pertunjuan Wayang Wong Millenial menampilkan lakon Cupu Manik Astagina, yakni kehidupan keluarga Rsi Ghotama dan Dewi Indradi beserta ketiga putranya : Dewi Anjani, Arya Bang, Arya Kuning. Dikisahkan bahwa sebelum berumah tangga, Dewi Indardi menerima anugerah berupa Cupu manik Astagina dari Dewa Surya. Anugerah itu oleh Dewi Indardi diberikan kepada putrinya, Dewi Anjani yang kemudian menjadi sumber konflik di keluarga Resi Ghotama. Konflik antar anggota keluarga akibat anugerah pemberian Dewa Surya inilah yang membuat Resi Ghotama marah. Pada akhirnya, Rsi Ghotama membuang benda ajaib tersebut ke tengah hutan. Kemarahan Resi Ghotama berdampak pada perubahan Dewi Indradi menjadi batu serta Arya Bang dan Arya Kuning berubah menjadi sosok kera.

Kisah Cupu manik Astagina (CMA) berintikan cerita prahara keluarga Resi Ghotama serta keberadaan benda ajaib yang dapat menjadi simbol kecanggihan teknologi (gadget) harus dikuasai oleh generasi Millenial. Inti dari kisah CMA ini adalah tentang keharusan generasi Millenial mencari ilmu pengetahuan yang diperlukan sebagai bekal hidup menghadapi tantangan persaingan era digital (Ruastiti, 2020; Karmini, 2017: 144-161).

Disamping orang dewasa, Seni Pertunjukan Wayang Wong Millenial juga didukung oleh generasi millenial Bali. Generasi millennial diantaranya yaitu generasi veteran (lahir 1926 - 1946), generasi Baby Boom (lahir 19461960), generasi X (lahir 1960-1980), generasi Y (lahir 1980-1995), generasi Z (lahir 1995-2010), dan generasi Alfa yang lahir tahun 2010 ke atas (Bencsik, dkk., 2016; Bennett et al., 2008). Pelibatan generasi millenial Bali ini penting agar Wayang Wong yang mulai redup dalam perkembangan industri seni pertunjukan di era digital saat ini bisa dibangkitkan, bahkan bisa diwarisi oleh generasi penerus.

Model Seni Pertunjukan Wayang Wong Millenial dengan kisah Cupu Manik Astagina ini sengaja dikemas sesuai selera generasi Millenial yang dituntut terampil teknologi 
digital dan kompeten. Cupu Manik Astagina mengisahkan tentang pusaka yang menjadi sumber konflik keluarga dan siswa di pasraman. Pada era digital saat ini, sumber data dan pengetahuan bukan berasal dari guru atau orang tua saja, tetapi juga dari media digital. Jaringan internet telah menyediakan "apa saja" yang bisa diakses oleh anak-anak secara online, kapan-pun dan dimana-pun. Secara pasti bahwa anak-anak tidak boleh hanyut dalam permainan game-game digital yang berpotensi merusak jam belajar mereka. Oleh karena itu, orang tua siswa juga harus melek teknologi digital. Mereka harus bisa mengarahkan dan mendampingi putra putrinya dalam belajar secara digital. Orang tua harus mampu berperan sebagai pendamping dan fasilitator bagi putra-putrinya dalam memanfaatkan teknologi digital.

Orientasi pendidikan di era digital saat ini bukan sebatas menyentuh dimensi kognitif, tetapi juga harus mampu menyentuh dimensi afektif dan psikomotorik untuk pembentukan karakter generasi millenial sebagai penerus bangsa. Oleh sebab itu, pengembangan kurikulum harus mengelaborasi kemampuan siswa pada dimensi kecakapan hidup mandiri, kemampuan hidup secara bersama, kreatif dan kritis. Proses pembelajaran perlu mengedepankan 'soft skills'dan melatih 'hard skills' sesuai minat dan bakat anak muda (Ruastiti, 2011: 241-245).

Secara komprehensif upaya mewujudkan karakter anak dapat ditempuh melalui proses pendidikan yang dilakukan sejak dini secara sinergis oleh empat pelaku utama pendidik yang sesuai dengan konsep catur guru. Dalam ajaran agama Hindu, konsep Catur Guru meliputi : (1) Guru Rupaka; (2) Guru Pengajian; (3) Guru Wisesa; (4) Guru Swadhyaya (Lastini dan Anggreni, 2018; Wahid dan K. Saddhono, 2017: 172-177).

Tabel 1 Implementasi Catur Guru dalam Seni Pertunjukan Wayang Wong Millenial

\begin{tabular}{|c|c|c|}
\hline No & $\begin{array}{l}\text { Komponen } \\
\text { Catur Guru }\end{array}$ & $\begin{array}{c}\text { Peran Strategis dalam Pendidikan } \\
\text { Karakter }\end{array}$ \\
\hline 1 & $\begin{array}{l}\text { Guru Rupaka } \\
\text { (orang tua) }\end{array}$ & $\begin{array}{l}\checkmark \quad \text { Sosok Resi Ghotama yang } \\
\text { mendidik ke-3 putra-putrinya } \\
\text { di lingkungan keluarga. } \\
\checkmark \\
\text { Keluarga merupakan wahana } \\
\text { pendidikan utama dan } \\
\text { pertama bagi generasi penerus } \\
\text { dalam menjalani kehidupan. } \\
\checkmark \quad \text { Memotivasi putra-putrinya } \\
\text { untuk rajin belajar, memiliki } \\
\text { mental kompetitif sesuai era } \\
\text { revolusi industri 4.0. }\end{array}$ \\
\hline
\end{tabular}

\begin{tabular}{|c|c|c|c|}
\hline 2 & $\begin{array}{l}\text { Guru } \\
\text { Pengajian (di } \\
\text { sekolah) }\end{array}$ & $\begin{array}{l}\checkmark \\
\checkmark \\
\checkmark\end{array}$ & $\begin{array}{l}\text { Mengembangkan kurikulum } \\
\text { seni-budaya } \\
\text { Menyampaikan pengetahuan } \\
\text { dan keteladanan } \\
\text { Memberikan pengetahuan dan } \\
\text { pendampingan kepada siswa } \\
\text { untuk mengenal seni-budaya, } \\
\text { termasuk Seni Pertunjukan } \\
\text { Wayang Wong Millenial. }\end{array}$ \\
\hline 3 & $\begin{array}{l}\text { Guru Wisesa } \\
\text { (pemerintah) }\end{array}$ & $\checkmark$ & $\begin{array}{l}\text { M e } \mathrm{n} \text { e } \mathrm{m} \text { b a } \mathrm{n} \mathrm{g} \mathrm{k} \text { a } \mathrm{n} \\
\text { kebijakan yang mendukung } \\
\text { pengembangan wayang } \\
\text { wong mielnial (Cupu Manik } \\
\text { Astagina) } \\
\text { Terciptanya situasi kondusif } \\
\text { untuk mendukung apresiasi } \\
\text { seni-budaya, teramsuk Seni } \\
\text { Pertunjukan Wayang Wong } \\
\text { Millenial. }\end{array}$ \\
\hline 4 & $\begin{array}{c}\text { Guru } \\
\text { Swadyaya } \\
\text { (Sang Hyang } \\
\text { Widhi) }\end{array}$ & $\checkmark$ & $\begin{array}{l}\text { Sumber atas segala nilai } \\
\text { kebenaran } \\
\text { Maha Pendidik kehidupan }\end{array}$ \\
\hline
\end{tabular}

(Sumber : Hasil kajian lapangan Ruastiti, 2021)

Sebagaiman dijelaskan pada Tabel 1, Seni Pertunjuan Wayang Wong Millenial yang menampilkan kisah Cupu Manik Astagina merupakan cermin dari pendidikan. Dalam ajaran agama Hindu Bali terdapat konsep catur guru yang harus diterapkan oleh umat Hindu : Pertama, guru rupaka, yakni kedua orang tua sebagai pendidik pertama dan utama di lingkungan rumah tangga. Orangtua adalah yang menjadi pelaku sosialisasi dan enkulturasi nilai-nilai budaya leluhur bagi anak-anaknya (Gidden, 20031 Tyas, 2018: 182-190).

Resi Ghotama adalah seorang Guru Rupaka, yakni sosok orang tua pendidik yang bertanggungjawab bagi para putranya. Dalam lingkup keluarga inilah Resi Ghotama mengajarkan nilai-nilai kehidupan, sopan santun dalam pergaulan sosial, serta ajaran dalam menghadapi masa depan. Dalam era digital, generasi Millenial harus siap mental menghadapi tantangan zaman. Mereka juga perlu lebih disiplin, mampu berkomunikasi, berkolaborasi, berpikir kreatif, memiliki keunggulan (competitive advantage), kritis dan siap berkompetisi dalam persaingan global. Mereka juga dituntut memiliki perilaku yang baik (behavioral attitude) dalam proses meningkatkan kompetensi diri. Berikut ini (gambar 1) adalah adegan Resi Ghotama sebagai Guru Rupaka sedang menasehati anak-anaknya.

Kedua, Guru Pengajian yaitu guru yang memberikan ilmu pengetahuan di sekolah. Pada era revolusi industry 4.0 dewasa ini, kedudukan guru di sekolah telah mengalami pergeseran. Mereka bukanlah satu-satunya sumber 


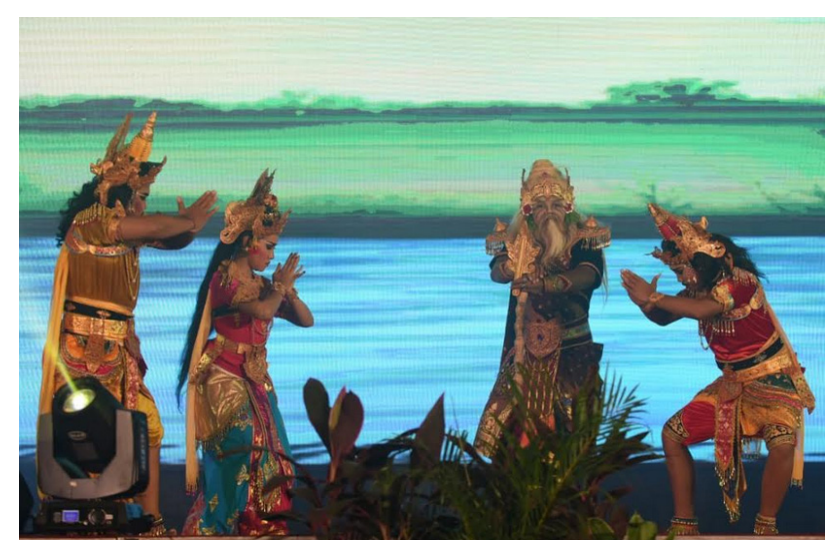

Gambar 1. Adegan Resi Ghotama menasehati ketiga anaknya (Dewi Anjani, Subali dan Sugriwa)

(Dokumentasi : Ruastiti, 2020)

yang menetukan pengetahuan siswa, tetapi guru kini lebih sebagai pendamping dan fasilitator siswa dalam memahami pengetahuan.

Ketiga, Guru Wisesa yakni pihak pemerintah selaku penentu kebijakan yang telah mendukung pengembangan Wayang Wong Millenial. Dinas Pendidikan dan kebudayaan serta Dinas Pariwasata telah mendukung agar seni-budaya Bali, termasuk pertunjukan Wayang Wong bisa tetap eksis sebagai media hiburan (tontonan) sekaligus sebagai tuntunan. Dukungan kebijakan pemerintah ini penting agar seni-budaya Bali, khususnya pertunjuan wayang wong bisa diwariskan kepada generasi penerus.

Kempat, Guru Swadhyaya, yakni Ida Sang Hyang Widhi sebagai sumber atas segala nilai kebenaran, keimanan dan maha pendidik kehidupan. Wayang Wong Millenial mengandung ajaran untuk selalu berbhakti kepada Tuhan sebagai maha pendidik kehidupan (Ruastiti dkk, 2020; Rai S. dkk, 2020). Hal ini tercermin bahwa terdapat persembahyangan bersama oleh pemain Wayang Wong Millenial sebelum mereka menggelar pementasan.

Keempat figur pendidik ini perlu dilibatkan secara sinergis dalam usaha mewujudkan proses pendidikan yang holistik kepada generasi penerus. Disamping memberikan keteladanan, proses pendidikan kepada generasi Millenial juga disampaikan secara langsung maupun tidak langsung dengan memanfaatkan media digital yang tersedia dalam arus revolusi industri 4.0. Proses belajar mengajar kini bisa dilakukan dengan sistem daring (e-learning). Dalam kaitan ini, anak - anak millennial kini cenderung lebih akrab (friendly) menggunakan gadget atau teknologi digital saat ini. Mereka bisa mengakses informasi apa saja yang ada di dalam dunia digital, baik informasi yang bersifat positif maupun yang negatif untuk pembentukan karakter generasi penerus. Disini, perlu disadari bahwa eksistensi media digital tidak sekadar mampu mengubah atau memperkuat opini, sikap dan perilaku, tetapi telah menjadi salah satu agen sosialisasi dalam menciptakan dan membentuk sikap, nilai, perilaku dan persepsi seseorang mengenai realitas sosial (Nurudin, 2003). Informasi dari internet dapat mempengaruhi perilaku pemakainya. Terhadap anak balita, media digital mampu mempengaruhi perkembangan motorik, perkembangan fisik, perkembangan neurologi, perkembangan kognitif, perkembangan moral, perkembangan bahasa dan perkembangan sosial (Santosa, 2015).

Agar anak-anak mampu menggunakan media digital secara kontsruktif dan edukatif, mereka memerlukan pendampingan orang dewasa. Guru-guru di sekolah dan orang tua di rumah wajib ikut campur tangan mengawasi, dan mendampingi putra-putrinya sejak usia dini dalam memanfaatkan gadget. Anak-anak yang yang terlibat sebagai pemain Wayang Wong Millenial adalah generasi penerus bangsa yang dipandang perlu melek teknologi digital yang berkembang pesat saat ini dalam arus revolusi industri 4.0. Sebagaimana trend pendidikan global di era digital, mereka pun harus dilatih dan didampingi memakai gadget untuk mendukung proses belajarnya.

Pendidikan karakter anak-anak sejak usia dini perlu ditunjang dengan paket kurikulum yang mampu memotivasi dan mengarahkan mereka agar bersikap responsif, kreatif dan kritis terhadap tantangan di era digital. Dalam hal ini, perlu diingat bahwa anak-anak sebagai generasi penerus tidak sekedar hanya mampu terampil dalam operasional teknologi terbarukan, tetapi mereka harus tetap menjadi generasi muda Bali, menjadi putra dan putri bangsa Indonesia yang membanggakan, yang memiliki dan memahami tradisi, seni-budaya, agama serta sejarah bangsanya.

Memasuki era digital, generasi penerus bangsa Indonesia dihadapkan pada tantangan, mereka harus menjadi generasi unggul, siap bersaing dalam milenial global masa depan. Pada saat ini hanya bangsa yang memiliki anak yang unggullah yang akan mampu bersaing. Oleh karena itu, bangsa Indonesia mesti menyiapkan generasi penerus bangsa yang kuat dan berkarakter unggul. Hanya melalui proses Pendidikan, setiap insan berkualitas dapat diwujudkan. Sebagaimana kualitas perlu dikonstruksi, dipertahankan secara internal dan dikembangkan untuk kepentingan kompetitif (Pradana dan Parwati, 2017; Pradana dan Pratiwi, 2021).

Sesuai tantanga era 4.0 , orientasi pendidikan karakter diharapkan mampu membentuk generasi kreatif, inovatif serta siap berkompetisi secara global. Mentalitas siap berkompetisi ini antara lain tercermin dalam perebutan cupu manik astagina oleh ketiga anak Bhagawan Ghotama. Upaya membentuk mental kompetitif dapat dicapai salah satunya dengan cara mengoptimalisasi penggunaan teknologi sebagai alat bantu pendidikan yang diharapkan mampu menghasilkan output yang dapat mengikuti atau mengubah zaman menjadi lebih baik. Pendidikan 
nasional berfungsi mengembangkan dan membentuk watak serta peradaban bangsa yang bermartabat dalam rangka mencerdaskan kehidupan bangsa, bertujuan untuk berkembangnya potensi peserta didik agar menjadi manusia yang beriman dan bertakwa kepada Tuhan Yang Maha Esa, berakhlak mulia, sehat, berilmu, cakap, kreatif, mandiri dan mampu menjadi warga negara yang demokratis serta bertanggung jawab (Pasal 3, UU No. 20/2003).

Upaya pendidikan yang mendorong generasi penerus mampu menguasai ilmu pengetahuan dan teknologi (Iptek) berbasis digital memang diperlukan dan penting agar mereka di masa depan bisa bersaing bersama bangsabangsa maju lainnya dalam perkembangan peradaban global. Akan tetapi, penguasaan Iptek itu perlu dibarengi dengan upaya melestarikan dan mengembangan senibudaya bangsa sendiri. Inovasi Seni Pertunjukan Wayang Wong Millenial adalah bagian dari upaya untuk melestarikan seni-budaya Bali yang kini tergempur oleh pengaruh grobalisasi dalam globalisasi.

\section{SIMPULAN}

Berdasarkan uaraian tersebut di atas dapat disimpulkan bahwa Catur Guru bagi umat Hindu Bali dikenal sebagai empat figur yang diyakini berpengaruh dalam proses pembelajaran. Guru Rupaka, Guru Pengajian, Guru Wisesa dan Guru Swadhyaya dalam tradisi Hindu Bali dipandang sebagai empat sumber pembejalaran terintegrasi. Oleh karena itu, capaian pembelajaran siswa secara eksternal tidak hanya disebabkan oleh para guru mereka di sekolah, melainkan dipahami pula disebabkan besarnya peranan orang tua, kepedulian pemerintah dan Ida Sang Hyang Widhi sebagai panutan mereka dalam proses pembelajaran.

Implementasi prinsip Catur Guru dalam Seni Pertunjukan Wayang Wong Millennial tersirat dalam lakon Cupu Manik Astagina diantaranya memuat tentang ajaran untuk senantiasa berbakti kepada Ida Sang Hyang Widhi (Guru Swadhyaya), Rsi Gotama selaku Guru Pasraman (Guru Pengajian) dan menghormati Rsi Gotama sebagai seorang kepala keluarga Gotama (Guru Rupaka). Dukungan pemerintah melalui Ristekbrin sebagai mitra pertunjukan dimaknai sebagai sebuah bentuk kepedulian Guru Wisesa yang telah diapresiasi oleh pelaku secara tanggungjawab dalam pementasan Wayang Wong Millennial.

\section{UCAPAN TERIMA KASIH}

Seni Pertunjukan Wayang Wong Inovatif yang dirancang khusus bagi generasi millennial adalah salah satu luaran hasil Riset Terapan Nasional (2019-2020). Atas terselenggaranya riset ini, izinkan kami mengucapkan terima kasih kepada pendukung riset, khususnya Direktorat Jendral Pendidikan, Kebudayaan, Riset dan Teknologi Republik Indonesia yang telah mendanai riset ini.

\section{DAFTAR RUJUKAN}

Astawa, I Nyoman Sidi. (2017). Catur Guru dalam Pemaknaan Hari Suci Saraswati Perspektif Filsafat Pendidikan Hindu. Jurnal Bawi Ayah, 8(2), 28-39.

Bencsik, A., Juhász, T., \& Horváth-Csikós, G. (2016). Y and Z Generations at Workplaces. Journal of Competitiveness, 6(3), 90-106. https://doi.org/10.7441/joc.2016.03.06

Bennett, S., Maton, K., \& Lisa Kervin. (2008). The "digital natives" debate: A critical review of the evidence. British Journal of Educational Technology, 39(5), 775786. https://doi.org/10.1111/j.1467-8535.2007.00742.x

Cahyono, A., B Hanggoro P. MH Basri. (2016). Tanda dan Makna Teks Pertunjukan Barongsai. MUDRA : Jurnal Seni Budaya, 31(1), 23-36. https://doi.org/10.31091/mudra. v31i1.246

Fathurrohman, Muhammad. (2016). Pengembangan Budaya Religius Dalam Meningkatkan Mutu Pendidikan. Jurnal TA'ALLUM, 4(1), 19-42. https://doi.org/10.21274/ taalum.2016.4.1.19-42

Giddens, A. (2003). The Constitution of So-ciety : Teori Strukturasi untuk Analisis Sosial (D. A. L. Sujono, Trans.). Pasuruan: Pedati.

Karmini, N W. (2017). Fungsi dan Makna Sastra Bali Tradisional Sebagai Pembentuk Karakter Diri. MUDRA : Jurnal Seni Budaya, 32(2), 144-161. https://doi. org/10.31091/mudra.v32i2.106

Kompri. (2015). Motivasi Pembelajaran Perspektif Guru dan Siswa. Bandung: PT. Remaja Rosdakarya Offset.

Lase, Delipiter. (2019). Education and Industrial Revolution. Jurnal Handayani, 10(1), 48-62.

Lickona, Thomas. (1991). Educating for Character, Mendidik untuk Membentuk Karakter. Jakarta: Bumi Aksara.

Mukhlis, Mulyasa. (2009). Standar Kompetensi dan Sertifikasi Guru. Bandung: PT Remaja Rosdakarya.

Natalia, Bonifasia Ekta Fima. (2021). Philosophical Basis on Education Principle of Taman Siswa on The Beginning of Its Estabelishment. AoEJ : Academy of Education Journal, 12(1), 15-21.

Nurudin. (2003). Komunikasi Massa. Malang: Pustaka Pelajar Yogyakarta.

Rai S., I Wayan, Ni Made Ruastiti, Yunus Wavom. (2020). Pura Agung Surya Bhuwana As A Media Strengthening Multikultural Awarness In Era 4.0. PalArch's Journal of Archaeology of Egypt/Egyptology, 17(9), 556-568. 
Rokhman, Fathur dkk. (2014). Character Education For Golden Generation 2045 (National Character Building for Indonesian Golden Years). Procedia-Social and Behavioral Sciences, 141(1), 1161-1165. https://doi. org/10.1016/j.sbspro.2014.05.197

Ruastiti, Ni Made, I Komang Sudirga, I Gede Yudarta. (2020). Model of Innovative Wayang Wong for Millenial Generation to Meet 4.0 Industrial Revolution Era in Bali. Journal of Environmental Treatment Techniques, 8(3), 999-1004.

Ruastiti, Ni Made, I Komang Sudirga, I Gede Yudarta. (2021). The Appreciation Of The Innovative Wayang Wong Performing Arts Through Digital Media. Psychology And Education, 58(1), 5241-5252. https://doi.org/10.17762/ pae.v58i1.2080

Ruastiti, Ni Made. (2011). The Concept Of Local Genius In Balinese Performing Arts. MUDRA : Journal of Art and Culture, 26(3), 241-245.

Ruastiti, Ni Made, I Komang Sudirga, I Gede Yudarta. (2021). Cultural Enculturation Strategies For Bali Millennial Generations in The Digital Age. Multicultural Education, 7(6), 288-296.

Santosa, Elizaberth T. (2015). Raising Children in Digital Era, Pola Asuh Efektif Untuk Anak di Era Digital. Jakarta : PT Gramedia.

Sartika, Lianda Dewi, Hermanu Joebagio, Susanto. (2020). Model Pembelajaran IPS Terintegrasi Nilai-Nilai Catur Guru Sebagai Civic Intellegence di Bali. Yupa : Historical Studies Journal, 4(1), 1-8.

Setiawati, Nanda Ayu. (2017). Pendidikan Karakter Sebagai Pilar Pembentukan Karakter Bangsa. Prosiding Seminar Nasional Tahunan Fakultas Ilmu Sosial Universitas Negeri Medan, 1(1), 348-352. Medan : UNM Press.

Suryosubroto. (2004). Manajemen Pendidikan di Sekolah. Jakarta : Rineka Cipta.

Tyas, G.P. (2018). Nilai Pendidikan Karakter Dalam Ragam Gerak Tari Srimpi Pandelori. MUDRA : Jurnal Seni Budaya, 33(2), 182-190. https://doi.org/10.31091/ mudra.v33i2.329

Wahid, A N., K Saddhono. (2017). Ajaran Moral Dalam Lirik Lagu Dolanan Anak. MUDRA : Jurnal Seni Budaya, 32(2), 172-177. https://doi.org/10.31091/mudra.v32i2.107

Pradana, Gede Yoga Kharisma. (2012). Diskursus Fenomena Hamil di Luar Nikah dalam Pertunjukan Wayang Joblar. Online Journal of Cultural Studies, 1(2), 11-27.
Pradana, Gede Yoga Kharisma. (2018). Implications of Commodified Parwa Shadow Puppet Performance For Tourism in Ubud, Bali. Journal of Business on Hospitality and Tourism, 4(1), 70-79. http://dx.doi.org/10.22334/ jbhost.v4i1.103.g111.

Pradana, Gede Yoga Kharisma. (2019). Sosiologi Pariwisata. Denpasar : STPBI Press.

Pradana, Gede Yoga Kharisma, Komang Trisna Pratiwi Arcana. (2020). Balinese Traditional Homestay in a Sustainable Tourism Entering Millennial Era. Journal of Xi'an University of Architecture and Technology, 12(3), 4208-4217. https://doi.org/10.37896/JXAT12.03/367

Pradana, Gede Yoga Kharisma, I Nyoman Suarka, Anak Agung Bagus Wirawan, I Nyoman Dhana. (2016). Religious Ideology of The Tradition of The Makotek in The Era of Globalization. Electronic Journal of Cultural Studies, 9(1), 6-10.

Pradana, Gede Yoga Kharisma, Komang Shanty Muni Parwati. (2017). Local-Wisdom-Based Spa Tourism in Ubud Village of Bali, Indonesia. Russian Journal of Agricultural and Socio-Economic Sciences, 8(68), 188196. https://doi.org/10.18551/rjoas.2017-08.22

Pradana, Gede Yoga Kharisma, Komang Trisna Pratiwi Arcana. (2021). Hasil Pengelolaan Homestay Bercorak Budaya Tradisional Bali Ditengah Pengaruh Perkembangan Trend Millennial di Sektor Pariwisata. Jurnal Ilmiah Hospitality Management, 11(1), 1-12. https://doi.org/10.22334/jihm.v11i1.172

\section{UCAPAN TERIMAKASIH / PENGHARGAAN}

Ucapan terima kasih disampaikan kepada Ristekbrin selaku mitra aktif penelitian sampai dengan penelitian ini dapat diselesaikan dalam bentuk artikel ilmiah. 